the medium to induce maximum vernalization, mustard embryos can be maximally vernalized even in glass-distilled water. Purvis ${ }^{3}$ has observed that excised embryo of rye, compared to the whole grain, requires longer duration of chilling to induce any acceleration of flowering. In the case of embryos of mustard T.102, however, the earliness in flowering (on percentage basis) induced by chilling for one and two weeks was greater in plants from embryos than plants from intact seeds.

A detailed report of this investigation, which is being financed by the Imperial Council of Agricultural Research, New Delhi, is being published elsewhere. B. Sen

S. C. Chakravarti

Vivekananda Laboratory, Almora, India.

'Sen, B., and Chakravarti, S. C., Nature, 157, 266 (1946).

'Gregory, F. G., and Purvis, O. N., Ann. Bot., 2, 237 (1938).

${ }^{3}$ Purvis, o. N., Ann. Bot., 8, 285 (1944).

${ }^{4}$ Gregory, F. G., and de Ropp, Nature, 142, 481 (1938).

\section{The Kerotakis Apparatus}

Some interest has been taken in the summary of my Royal Institution lectures ${ }^{1}$, and Dr. E. C. Stathis, of the University of Athens, has directed attention to a paper ${ }^{2}$ by Prof. K. Zengholis, of that University, on the kerotakis apparatus. Hoefer ${ }^{3}$, who reproduced a diagram of it from a Paris manuscript ${ }^{4}$, which ${ }^{5}$ is copied from the old Venice manuscript ${ }^{6}$, called it a 'bain-Marie a kérotakis', explaining that it was not a water bath (as this name would suggest) but a sand- or ash-bath. The same name is used by Berthelot?, who, however; gives a more adequate description of the apparatus, and in particular indicates that the name comes from that of the triangular palette used by painters in encaustic for keeping liquid the wax pigments. He gives several pictures of the apparatus, which make. it clear that there were several forms, probably destined for different uses. The one under consideration is that which I described ${ }^{8}$ in 1929 as a small charcoal brazier, surmounted by a piece of apparatus the use of which is not immediately obvious, and in my lecture I stated that it was used for sublimation. The invention of this apparatus is attributed ${ }^{\theta}$ to the early chemist Maria the Jewess (first century A.D.).

Prof. Zenghelis points out that, since the part of the apparatus above the hot plate is described as an inverted clay pot $\left(\varphi[\alpha \lambda \eta)^{10}\right.$ luted to the plate, the effects of heat on the materials inside could not be seen; and since the plate is shown in some representations ${ }^{11}$ as projecting beyond the pot, he suggests that the ends served to support substances which by their fusion, evaporation or sublimation indicated the temperature inside the pot. Such a method of measuring temperature is still in use in the Seger cones put into pottery furnaces, and, it may be added, in preparations which change colour at definite temperatures and frequently appear in modern patents ${ }^{12}$. The kerotakis thus served as a kind of thermometer.

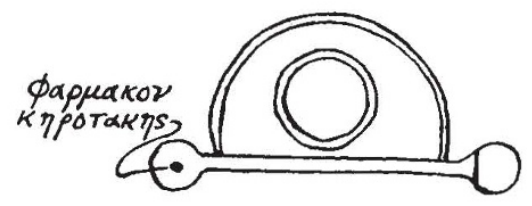

The correctness of this suggestion seems to be supported by a drawing which has not, so far as I am aware, been published. I give a sketch of this which I made in 1924 from a Paris manuscript ${ }^{13}$. It will be seen that there is a line joining the words

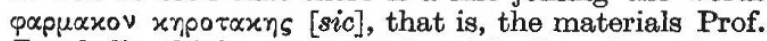
Zenghelis thinks were used, with the edge of the plate, where he says they were placed.

There were, as I pointed out in my lecture, rival schools of chemists, the one whose teachings are mostly reproduced in the extant manuscripts being that of Demokritos. Another school seems to have followed Hermes. The commentator Olumpiodoros ${ }^{14}$ quotes Agathodaimon as saying, from Hermes: "let it

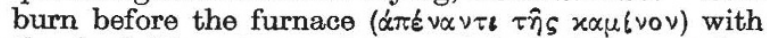
the bark-like pieces of the red kobathia $(\varkappa \omega \beta \alpha \theta l \alpha)$ $\left[=\right.$ red arsenic sulphide, $\mathrm{As}_{2} \mathrm{~S}_{2}$ ]. For the smoke of the kobathia, being white $\left[=\mathrm{As}_{2} \mathrm{O}_{3}\right]$, whitens bodies [ = metals such as copper]." This is the method used with such ill success by Neilos (see my lecture), who used a common fireplace instead of the refined kerotakis apparatus invented by Maria, of the rival school.

Interest in experiments and apparatus seems to have come into early chemistry from a Jewish source. It was foreign to Greek science; Aristoteles and Theophrastos were excellent at description, and in biology, which until recently was purely observational and descriptive, and hence their accounts seem so modern. They had little or no interest in experiment, and in Greek tradition apparatus was, apart from engines of war, almost entirely confined to toys, which reached a climax in the Byzantine period. To the two streams of Greek tradition, descriptive. biological treatment, and superstitious works such as the lapidaries and bestiaries, a third was added in the earliest chemistry, and this one, characterized by an interest in experiment and in the devising of apparatus, is uniformly ascribed to a Jewish source. Even if Wellmann's ${ }^{15}$ thesis of an Essene origin is not accepted, his general theory seems to be plausible. I propose to develop this line of thought in detail elsewhere ${ }^{16}$.

50 Maids' Causeway, Cambridge.

${ }^{1}$ Nature, 159, 81 (1947).

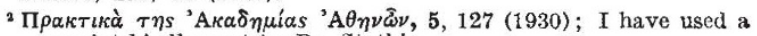
reprint kindly sent by Dr. Stathis.

s "Histoire de la Chimie", 1, 284 (Paris, 1866).

- $B N 2249$ grec.

B Berthelot, "Collection des anciens alchimistes grecs", 1, 129 (Paris, 1887-88).

- Marcianus, 299, xii cent.

7 op. cit., 148.

8 "Everyday Chemistry", Fig. 65D, 68 (London, 1929); from $B N 2325$ grec, f. 84 (xiii cent.).

- Berthelot, op . cit., 2, 238; Zosimos quoting Agathodaimon.

10 This name was also used in the manuscripts for a flask or phial, the latter being so labelled in the drawings.

11 Marcianus 299, f. $196=$ Berthelot, op. cit. 1, 148, Fig. 24 ; already in Hoefer, op. cit., from Paris 2249, f.102v (not "fol.'2 verso" as he says).

${ }^{12}$ For example, I.G. Farben-Ind., French Pat. 922308 (1937) ; see Tyte, Proc. Inst. Mech. Eng., 152, 226 (1945).

${ }^{13} B N 2249$, f.103.

14 Berthelot, op . cit., 2, 84; for a collection of statements of Hermes in the chemical manuscripts, see Festugière, A. J., "La Révélation d'Hermès Trismégiste", 1, 240f. (Paris, 1944).

15 Wellmann, M., "Die $\Phi v \sigma \iota \kappa a ́$ des Bolos Demokritos und der Magier Anaxilaos aus Larissa", Abhl. Preuss. Akad. Wiss., phil.-hist. Kl., 1921, No. iv ; Festugiere, op. cit., p. 197, thinks the correct name is 'Bolos the Demokritan', and that he may be the same as Demokritos the alchemist; I think the latter is doubtful.

16 The relation to the conjuring tricks described by Hippolytos and the Jewish Gnostic, Markos, will also be discussed. Most of the 